\title{
Rescatar al consumidor sobre endeudado para la reactivación y crecimiento con equidad de la Argentina
}

Rescuing the consumer in debt for the reactivation and growth with equity of Argentina.

Resgatando o consumidor em divida pela reativação e crescimento com patrimônio da Argentina.

Sauvetage du consommateur endetté pour la réactivation et la croissance avec équité de l'Argentine

通过阿根廷股权重新激活负债消费者以恢复和增长

Hernán Albisu ${ }^{1}$ | Universidad Nacional de La Plata

Revista Derechos en Acción ISSN 2525-1678/ e-ISSN 2525-1686

Año 4/No 11 Otoño 2019 (21 marzo a 21 junio), 176-208

DOI: https://doi.org/10.24215/25251678e273

ORCID: https://orcid.org/0000-0001-9983-9348

Recibido: 17/02/2019

Aprobado: 25/04/2019

Resumen: El trabajo aborda el problema del consumidor sobreendeudado, que está está en un estadio anterior a la insolvencia o cesación de pagos. Los primeros escalones son, normalmente, el pago a cuenta de deudas, compromisos sobre su renta actual o futura que, aunque estén siendo abonados generan la caída en el nivel de vida, para terminar desembocando finalmente -ahí sí- en la insolvencia y la cesación de pagos. Esta situación se genera cuando el consumidor seducido por las líneas de crédito y la consecuente publicidad llega a endeudarse a niveles que comprometen sus posibilidades de pago y, de esta forma, se configura un

1 Abogado (UNLP). Escribano (UNLP). Diplomado en DESC (UM). Maestrando en Derechos Humanos (IDH-UNLP). mail: ezequielrgalvan@gmail.com . 
exceso de deuda en donde la responsabilidad de los dadores de crédito aparece configurada. Existe un nuevo estilo de vida consumista que propone la gratificación del presente versus la financiación futura y, por otra parte, se han modificado las bases económicas de los consumidores. Ahora bien, cuando la persona advierte su nivel de endeudamiento, que sobrepasa su capacidad económica, deviene la situación de crisis y la necesidad de reestructurar sus deudas. Concluye que donde hay pobreza y hambre no hay mercado. Donde no hay mercado, no hay inversión. Donde no hay inversión, no hay empleo. Concluye que se debe ayudar al saneamiento de la situación del consumidor sobreendeudado, y permitirle volver a niveles de vida dignos, van en la dirección correcta para aportar a la reactivación y crecimiento con equidad que necesita nuestro país.

Palabras claves: Consumidor. Endeudamiento. Derechos

Abstract: The paper addresses the problem of the over-indebted consumer, who is in a stage prior to insolvency or default. The first steps are usually the payment on account of debts, commitments on their current or future income that, although being paid, generate the fall in the standard of living, eventually leading to insolvency and cessation of payments. This situation is generated when the consumer seduced by the lines of credit and the consequent advertising becomes indebted to levels that compromise their payment possibilities configuring an excess of debt where the responsibility of the credit providers appears configured. There is a new consumerist lifestyle that proposes the gratification of the present versus future financing and, on the other hand, the economic bases of consumers have been modified. Now, when the person notices his level of indebtedness, which surpasses his economic capacity, the crisis situation becomes and the need to restructure his debts. He concludes that where there is poverty and hunger there is no market. Where there is no market, there is no investment. Where there is no investment, there is no employment. He concludes that we must help to clean up the situation of the over-indebted consumer, and allow him to return to decent living standards, they are going in the right direction to contribute to the reactivation and growth with equity that our country needs.

Keywords: Consumer. Indebtedness. Rights 
Resumo: 0 trabalho aborda o problema da sobre-endividados consumidor, que é está em um estado anterior à insolvência ou padrão. Os primeiros passos são, normalmente, o pré-pagamento da dívida, compromissos sobre sua renda atual ou futuro que, embora estão sendo pagos geram a queda no nível de vida, para terminar ao final na insolvência e a cessação de pagamentos. Esta situação é gerada quando o consumidor seduzido por linhas de crédito e a consequente publicidade alcança a endividar-se a níveis que comprometem sua capacidade de pagamento e, assim, se configura o endividamento excessivo onde a responsabilidade do prestadores de crédito aparece configurada. Há um novo estilo de vida consumista que propõe a gratificação do presente versus o financiamento futuro e, por outro lado, foram modificadas as bases econômicas dos consumidores. Agora bem, quando a pessoa vê a sua dívida, o que excede a sua capacidade económica, a situação de crise se torna e a necessidade de reestruturar suas dívidas. Conclui que onde há pobreza e fome não há mercado. Onde não há mercado, não há investimento. Onde não há investimento, não há emprego. Conclui que deve-se ajudar ao saneamento da situação do consumidor super-endividado, e permitirIhe retornar ao nível de vida digno, vai na direção certa para contribuir a reativação e crescimento equitativo que nosso país precisa.

Palavras-chave: Consumidor. Endividamento. Direitos.

Résumé: Dans cet article, nous analysons le problème du consommateur surendetté, qui se trouve dans une phase précédant l'insolvabilité ou la cessation des paiements. Les premières étapes sont, normalement, le paiement sur compte de dettes, engagements sur les revenus actuels ou futurs qui, bien qu'ils soient payés, entraînent la baisse du niveau de vie, conduisant finalement à l'insolvabilité et au défaut. Cette situation est générée lorsque le consommateur séduit par les lignes de crédit s'endette à des niveaux compromettant sa capacité de paiement. De cette façon, un excès de dette est configuré lorsque la responsabilité des créanciers apparaît configurée. II y a un nouveau style de vie du consommateur qui propose la gratification du présent contre le financement futur et d'autre part, les bases économiques des consommateurs ont été modifiées. Lorsque la personne s'aperçoit que son niveau d'endettement dépasse sa capacité économique, elle devient une situation de crise et la nécessité de restructurer ses dettes. Là où il y a pauvreté et faim, il n'y a pas de marché, où il n'y a pas de marché, il n'y a pas d'investissement. Là 
où il n'y a pas d'investissement, il n'y a pas d'emploi. II doit contribuer à améliorer la situation du consommateur surendetté lui permettant de retrouver un niveau de vie décent. Cette aide contribue à la réactivation et à la croissance avec l'équité dont notre pays a besoin.

Mot-clés: Consommateur-Endettement-Droits.

摘要: 该工作解决了负债过重的消费者问题, 该问题处于破产或停止 支付之前的阶段。第一个步骤通常是债务的预付款, 其当前或未来收 益的承诺, 即使他们仍然订户产生生活水平的下降, 最终导致终有自 己变成破产和戒烟付款出现这种情况时, 通过信贷额度和随之而来 的宣传诱惑消费者进入债务水平是影响其支付, 因此过度负债设置 到出现度外信用责任能力配置。有由当前与未来的融资和, 在另一方 面, 满足提出了一个新的消费生活方式, 改变了消费者的经济基础。 现在, 当人看到它的债务, 这超出了其经济承受能力, 成为危机和需 要重组其债务。结论是, 贫穷和饥饿在没有市场。没有市场的地方就 没有投资。没有投资的地方就没有就业机会。它的结论是应该帮助的 过度负债消费的情况有所改善, 并让他返回到体面的生活水平, 走在 正确的方向, 以促进我们的国家需要恢复和公平的增长。

关键字: 消费者。负债。责任

\section{Introducción}

La sociedad capitalista vive por la búsqueda de lucro y por el consumo. El consumo es fomentado por todos los medios y se incentiva y enaltece cualquiera fuere la capacidad de pago del consumidor.

El mercado y en él, las grandes corporaciones, se valen de la publicidad para crear necesidades, y además, se otorgan múltiples modalidades de operaciones de crédito para la adquisición de bienes y servicios.

Uno de las características contemporáneas de la comercialización, es que se establece una subordinación estructural del consumidor con relación a las empresas que, en la práctica, se traduce en contratos de adhesión o con cláusulas predispuestas, en donde no existe posibilidad alguna de negociación. 
Por eso, con una economía de mercado que se encuentra en manos de los sectores de las corporaciones que fijan los precios y las condiciones de comercialización a las que nos vemos sometidos, las prácticas comerciales que estas llevan adelante, se vuelven muchas veces abusivas con las consecuencias nocivas para el consumidor.

De tal modo, el consumidor seducido por las líneas de crédito y la consecuente publicidad llega a endeudarse a niveles que comprometen sus posibilidades de pago y, de esta forma, se configura un exceso de deuda en donde la responsabilidad de los dadores de crédito aparece configurada.

Existe un nuevo estilo de vida consumista que propone la gratificación del presente versus la financiación futura $\mathrm{y}$, por otra parte, se han modificado las bases económicas de los consumidores. Ahora bien, cuando la persona advierte su nivel de endeudamiento, que sobrepasa su capacidad económica, deviene la situación de crisis y la necesidad de reestructurar sus deudas.

En ese contexto, el sobreendeudamiento del consumidor constituye un fenómeno totalmente distinto a la de la crisis de la empresa y hoy carece de encuadramiento normativo específico en nuestro país.

El consumidor es un deudor que no tiene activos o, si los tiene, son mínimos. Su capacidad económica es la de generar ingresos con su trabajo y los bienes comprometidos son los indispensables para una vida digna ${ }^{2}$.

\section{Radiografía de un consumidor sobreendeudado}

Daniel tiene 51 años, es empleado municipal en la comuna de un partido del interior de la Provincia de Buenos Aires desde

\footnotetext{
2 JUNYET BAS, Francisco, EN TORNO A LAS ALTERNATIVAS DE SANEAMiento PARA EL DEUDOR SOBREENDEUDADO. A propósito de la descarga del pasivo del consumidor y un procedimiento específico que habilite una segunda oportunidad para su reinserción socioeconómica y por ende, para una vida digna. Pags 3-4. https://www.institutoiberoamericanoderechoconcursal.org/images/eventos/congreso_uruguay/trabajos_investigacion/ otros/Junyent\%20\%20sobrendeudamiento\%2019\%20de\%20Abril\%202017.pdf
} 
el año 1989. Tiene 7 hijos, a los que con mucho esfuerzo y sacrificio les trató de dar la mejor vida y educación posible.

Desde hace 10 años aproximadamente tuvo que recurrir a métodos de financiamiento informales para subsistir, no pudiendo hacer más frente a ellos, atento al aumento del costo de vida (tarifas de servicios públicos, alimentación básica, vestimenta, educación, salud, esparcimiento) y el incremento en los intereses de cualquier medio de financiación (tarjeta de crédito, préstamos personales, etc.). Sumando a ello aumentos salariales que, como es de público conocimiento, no llegan a compensar con sus incrementos los mayores costos aludidos, fundamentalmente en los últimos 3 años.

Para poder afrontar tales obligaciones se vio en la necesidad de realizar horas extras (149 por mes) no teniendo ni fines de semana ni feriados, trabajando de lunes a lunes 10 horas por día.

Sin importar los esfuerzos realizados no puede hacer frente a sus obligaciones. Por eso le es imposible abonar las deudas reclamadas y las convenidas, ya sea por embargos judiciales, descuentos directos de sus haberes, códigos de descuento o descuento directo en su cuenta bancaria. De un sueldo neto de bolsillo de $\$ 21.000$, le descontaban $\$ 14.500$, afrontando el resto del mes con solo $\$ 6500$ para mantener a su familia.

Lo expuesto obligó a incurrir en un financiamiento fuera de la plaza bancaria para pagar los intereses de las deudas convenidas y los gastos mensuales de una familia numerosa y humilde.

Estas prácticas lo fuerzan a pagar tasas de interés a cifras incalculables y él -como consumidor/trabajador- se vio encerrado en un círculo vicioso que solo logró endeudarlo más día a día.

Para Daniel, prolongar la presentación de su propia quiebra era dilatar la agonía que él venía padeciendo y que padecen hoy en día muchos asalariados.

La situación se agrava en el sentido que no tiene margen para trabajar más horas y cumplir con sus obligaciones. 
Tampoco, en un análisis realista de la situación económica que atraviesa nuestro país, fundamentalmente en lo referido al mercado laboral -y el mercado de bienes y servicios en general- le permiten mediante el trabajo autónomo, poder incrementar sus ingresos.

Por eso en este caso puntual y como es el caso de miles de personas trabajadoras, no teniendo una mejor expectativa de poder cumplir con sus deudas, sin dejar de brindarle lo mínimo e indispensable a su familia para su subsistencia, no encontró otra salida que el pedido de su propia quiebra.

\section{III. ¿Qué es el sobreendeudamiento?}

No hay consenso entre los especialistas que nos dé una única definición de lo que es el sobreendeudamiento. Esto es así quizás por su cercanía o similitud con la insolvencia y la cesación de pagos, presupuesto fundamental que activa la aplicación de la ley concursal en nuestro país ${ }^{3}$. Pero no obstante ello, no son lo mismo.

El ante proyecto de Ley de Defensa del Consumidor elaborado por especialistas para el Ministerio de Justicia y Derechos Humanos, que seguramente tendrá tratamiento en el Congreso durante este año 2019, define al sobreendeudamiento del consumidor "...como la situación caracterizada por la grave dificultad para afrontar el cumplimiento de las obligaciones exigibles o de pronta exigibilidad, que compromete el acceso $y$ el goce de bienes esenciales"

El consumidor sobreendeudado, está en un estadio anterior a la insolvencia o cesación de pagos. Los primeros escalones

\footnotetext{
3 Artículo 1 Ley 24.522 de Concursos y Quiebras (LCO) “El estado de cesación de pagos cualquiera sea su causa y la naturaleza de sus obligaciones a las que afecte, es presupuesto para la apertura de los concursos regulados en esta ley, sin perjuicio de los dispuesto por los artículos 66 y 69"

4 https://www.justicia2020.gob.ar/wp-content/uploads/2018/12/Anteproyecto-LeyDefensa-del-Consumidor-_VFD_.pdf
} 
son, normalmente, el pago a cuenta de deudas, compromisos sobre su renta actual o futura que, aunque estén siendo abonados generan la caída en el nivel de vida, para terminar desembocando finalmente -ahí sí- en la insolvencia y la cesación de pagos (Tal como vimos en la historia de Daniel).

El sobreendeudamiento implica un cumplimiento forzado de las obligaciones, con un gran desgaste, pero cumplimiento al fin. La insolvencia significa el fin de esta situación y su incumplimiento 5 .

Es difícil definir precisamente el concepto por las dificultades que genera, entre otras, establecer cuando el endeudamiento es parte de una operación regular o normal para acceder al mercado de bienes y servicios, y cuando se transforma en una situación no deseada y crítica, perjudicial para el propio consumidor y para el sistema. La cuantificación del endeudamiento es una fuente de divergencia ${ }^{6}$ que no permite una única definición del sobreendeudamiento a pesar de algunos intentos por identificar fórmulas o modelos para medirlo ${ }^{7}$.

\section{III.1 Sobreendeudamiento activo y sobreendeudamiento pasivo}

Lo que es quizás más fácil de esquematizar es la forma en la que llega un consumidor al sobreendeudamiento. Identificando una forma activa y otra pasiva.

Se considera sobreendeudamiento activo a aquel donde el particular acude al financiamiento y se endeuda en exceso. El deudor contrae más obligaciones de las que puede afrontar.

\footnotetext{
5 Anchaval, Hugo, Insolvencia del Consumidor, Editorial Astrea, Buenos Aires, 2011, p. 31.

6 Ver Dictamen del Comité Economico y Social Europeo sobre "El crédito y la exclusión social en la sociedad de la abundancia" en https://eur-lex.europa.eu/legal-content/ES/TXT/ ?uri=uriserv:OJ.C_.2008.044.01.0074.01.SPA

7 En el trabajo titulado "Study of the Problem of Consumer Indebtedness: Statistical Aspects" se identifican tres fórmulas o modelos para medir el sobreendeudamiento: el modelo administrativo, el modelo subjetivo y el modelo objetivo. http://citeseerx.ist.psu.edu/viewdoc/download?doi=10.1.1.183.3320\&rep=rep1\&type=pdf
} 
El sobreendeudamiento pasivo es el que se desencadena como consecuencia de hechos posteriores al nacimiento de las obligaciones del deudor y por causas no imputables al particular afectado.

Si bien esta clasificación binaria sirve para graficar diferentes situaciones, la vida real nos muestra que el consumidor cae con mucha frecuencia por una retroalimentación de ambos tipos.

Sin ir más lejos, las crisis sistémicas son grandes productores de diversas catástrofes sociales, entre las que se encuentran el endeudamiento y el empobrecimiento de la población.

En esos marcos de crisis, las decisiones de las empresas y los gobiernos golpean en la economía de las personas y las familias, directamente en las previsiones presupuestarias que tenían previamente, en la disponibilidad de los recursos, en su capacidad de gestión frente al riesgo sobreviniente, en la conservación del ahorro y en el regular cumplimiento de los compromisos asumidos con anterioridad ${ }^{8}$.

La actualidad de nuestro país es una clara muestra de ello. Algunas medidas o situaciones que vemos hoy en día:

- Despidos en el sector público y privado

- Reducción o recorte de salarios

- Implementación de políticas monetarias y cambiarias que afectan el poder adquisitivo de la moneda (devaluación).

- Marcada pérdida del poder adquisitivo del salario con respecto a la inflación.

En un reciente artículo del diario La Nación titulado "Crece la cantidad de usuarios que toman préstamos para pagar los aumentos de tarifas" "se puede ver con claridad como las

\footnotetext{
8 Ver JAPAZE, María Belén, Sobreendeudamiento del Consumidor: remedios preventivos y de saneamiento, Bibliotex, San Miguel de Tucumán, 2016, pags. 34-36.

9 Ver TERRILE Sofía, en https://www.lanacion.com.ar/2218973-crece-la-cantidad-deusuarios-que-toman-prestamos-para-pagar-los-aumentos-de-tarifascrece-la-cantidadde-usuarios-que-toman-prestamos-para-pagar-los-aumentos-de-tarifas
} 
decisiones del Estado en materia de energía y combustibles dan de lleno en la economía doméstica de los consumidores, impidiéndoles cubrir erogaciones indispensables como los servicios básicos con su ingreso corriente. Dice el mencionado artículo "En el último trimestre de 2018, la fintech (empresas que mezclan finanzas y tecnología) de pago digital y préstamos personales Moni verificó un aumento del $45 \%$ en la cantidad de préstamos solicitados para pagar servicios en comparación con el mismo período del año anterior. El monto promedio que pidieron los usuarios fue de $\$ 2750$ a una tasa nominal anual (TNA) del 65\% -a ese porcentaje bay que sumarle otros gastos para obtener el costo financiero total (CFT)- y una comisión por uso de la plataforma, que en el caso de los préstamos es de \$500, aproximadamente.... En general, son empleados en relación de dependencia que reciben un salario de $\$ 32.000$ mensuales, por encima del ingreso medio. Según el Indec, en el tercer trimestre de 2018, al menos la mitad de los trabajadores asalariados ganaba sueldos mensuales por debajo de los \$15.000.”

En un lúcido análisis político de la actualidad de este tema, Mónica Peralta Ramos expresa “...este gobierno (en referencia al del Ing. Mauricio Macri) ba transformado a la energía en el campo de importancia estratégica para que un puñado de grandes corporaciones absorban masivamente los ingresos de la población, el excedente económico y la riqueza acumulada en el país. Los precios de las tarifas y de los combustibles afectan directamente todo lo que se produce y consume en las sociedades modernas. Controlar la producción de energía y dolarizar sus precios implica apropiarse de la gallina y de los huevos de oro que produce. Esto ha derivado en un tarifazo constante y sin limites...el tarifazo inunda a la estructura productiva, golpea a las empresas y a la población, y genera nuevo endeudamiento a fin de afrontar un costo mensual que no puede ser solventado con salarios, ingresos y rentabilidad cada vez más deteriorados. El pago en cuotas de tarifas cada vez más onerosas y el crecimiento exponencial de los intereses de esta deuda acumulada hacen del tarifazo un vehículo del 
endeudamiento financiero de los sectores más vulnerables de la población”. ${ }^{10}$

Definitivamente, a nuestra población, hoy en día, hay que darle una posibilidad de salida a la asfixia generada por el endeudamiento domestico que fue generado por situaciones externas a su voluntad, con las cuales nada tuvieron que ver, ni pudieron incidir en ellas.

\section{Tratamiento Legal al consumidor sobreendeudado en la actualidad Argentina. Un régimen costoso y engorroso que no incentiva la presentación de soluciones}

Ahora bien, tomando de ejemplo o caso puntual el de una persona como Daniel, con su realidad y contexto económico descripto, ¿Que herramientas le brinda nuestro ordenamiento para intentar solucionar sus problemas y a la vez subsistir dignamente?

En nuestro país, el régimen concursal comprende a todos los deudores en estado de cesación de pagos; personas jurídicas (sociedades comerciales, asociaciones sin fines de lucro, entidades mutuales, etc.) y personas físicas (empresarios y no comerciantes, profesionales liberales, cuentapropistas, asalariados, jubilados, amas de casa, etc.). Específicamente la Ley 24.522 de Concursos y Quiebras dedica dos artículos específicos a la figura de los "Pequeños Concursos y Quiebras" que es en la Argentina, la única vía posible para intentar superar la situación de insolvencia de los consumidores.

El artículo 288 de la norma dice: "Concepto. A los efectos de esta ley se consideran pequeños concursos y quiebras aquellos en los cuales se presente, en forma indistinta cualquiera de estas circunstancias:

1. Que el pasivo denunciado no alcance el equivalente a trescientos (300) salarios mínimos vitales y móviles.

\footnotetext{
10 Ver PERALTA RAMOS, Mónica, "Usura, Tarifazo y Geopolitica” en https://www.elcohetealaluna.com/usura-tarifazo-y-geopolitica/
} 
2. Que el proceso no presente más de veinte 20) acreedores quirografarios.

3. Que el deudor no posea más de veinte (20) trabajadores en relación de dependencia sin necesidad de declaración judicial".

Y agrega el artículo 289: "Régimen aplicable. En los presentes procesos no serán necesarios los dictámenes previstos en el artículo 11, incisos 3 y 5, la constitución de los comités de acreedores y no regirá el régimen de supuestos especiales previstos en el artículo 48 de la presente ley. El controlador del cumplimiento del acuerdo estará a cargo del síndico en caso de no haberse constituido comité de acreedores. Los honorarios por su labor en esta etapa serán del 1\% (uno por ciento) de lo pagado a los acreedores".

Es casi unánime la crítica de los autores a este capítulo de la ley, ya que, como indican solo se limitaron a bautizarlos sin fijar un procedimiento que aligerase los pasos que hacen al trámite común en materia concursal, ya que por más pequeña que sea la quiebra o pequeño el concurso, tramitará como el régimen común. ${ }^{11}$

Las diferencias del trámite indicadas en el art. 289 de la LCQ, no son significativas por lo que la duración del proceso, los requisitos de presentación, la publicación edictal, el régimen de insinuación y revisión de créditos, sus accesorios, los principios concursales, las tasas tributarias, los funcionarios concursales y sus honorarios, el mecanismo de obtención de mayorías, los supuestos de quiebra indirecta, el régimen de los hipotecarios y muchísimos otros institutos tiene aplicación similar, sin distinguir pequeños y grandes concursos. ${ }^{12}$

Como veremos seguidamente, me animo a decir que para los operadores que deberían intervenir en este tipo de procesos

\footnotetext{
11 MAFFIA, Osvaldo J., La Ley de Concursos comentada, T II, Lexis Nexis, BA, Buenos Aires, 2002, p. 373.

12 JUNYET BAS, Francisco - MOLINA SANDOVAL, Carlos A., Facultades del Juez concursal, Advocatus, Córdoba, 2004, pag 280.
} 
judiciales, no hay ningún tipo de incentivo real que provoque su actuación constante. Y esto es así porque, como veremos, este tipo de quiebras normalmente finalizan en lo que le Ley denomina clausura por falta de activo ${ }^{13}$. Cuando ese deudor quebrado es un consumidor que no tiene bienes como propietario y su único ingreso es el salario o una jubilación, normalmente no quedan luego de la verificación de créditos, recursos para pagar los gastos del proceso.

Ergo, el consumidor sobreendeudado quedará desprotegido y a merced de los actores del mercado financiero.

Ahora bien, supongamos que el consumidor sobreendeudado logra vencer los obstáculos sistémicos y logra el patrocinio de un abogado ¿Qué sucede en la práctica cotidiana con su quiebra?

Veremos que al Consumidor sobreendeudado, cuando quiebra y entra en el proceso falencial, le ocurre lo siguiente:

- Pierde la capacidad de administrar y disponer sus bienes (y los que adquiera hasta la rehabilitación), que quedan en manos del síndico sorteado por el juzgado, hasta el momento de la rehabilitación (un año desde la sentencia de quiebra) (artículos 107 y 109 LCQ).

La ley establece excepciones a los bienes sobre los cuales se pierden estas facultades (artículo 108 LCQ), principalmente: Los derechos no patrimoniales; los bienes inembargables; Como por ejemplo la parte del sueldo que no es embargable (hasta un salario mínimo vital y movil -actualmente $\$ 12.500$-, un $10 \%$ cuando no excede al doble del salario mínimo y vital y hasta un $20 \%$ cuando lo excede, según el artículo 1 del Decreto 484/87 y artículo 120 y 147 de la Ley de Contrato de Trabajo); o el inmueble destinado a vivienda

\footnotetext{
13 Artículo 232 1er parr., Ley 24.522 de Concursos y Quiebras (LCQ) “Debe declararse la clausura por falta de activo, si después de realizada la verificación de los créditos, no existe activo suficiente para satisfacer los gastos del juicio, incluso los honorarios, en la suma que prudencialmente aprecie el juez"
} 
constituido como bien de familia por deudas anteriores a dicha constitución (arts. 242, 244, 246, 249 CCyCN).

- Se levantan todos los embargos en el salario y todas las retenciones bancarias sobre el mismo (es posible que esto lo sea con los límites vistos). El levantamiento de todas las retenciones o embargos es debido a la ineficacia de los pagos hechos por el fallido, con posterioridad a la declaración de quiebra (art. 109, LCQ) y la orden judicial a terceros para que entreguen los bienes del fallido al síndico (art. 88, inc. $3^{\circ}$, LCQ), la incautación correspondiente (art. 177, LCQ) y el carácter de bien exento del desapoderamiento del salario (art. 108, inc. $\left.7^{\circ}, \mathrm{LCQ}\right)$ )

- Se declara su inhibición general en todos los registros de bienes

¿Cómo afecta a los acreedores?

- Limita la posibilidad del cobro por toda deuda anterior a la quiebra a lo producido con la liquidación de los bienes disponibles, y solo los acreedores que se presenten a probar su crédito (artículo 15 y 126 LCQ)

- Vencen los plazos de todas las deudas, volviéndose exigibles (artículo 128 LCQ)

- Se suspende el cobro de intereses (artículo 129 LCQ)

- Todos los juicios abiertos o los que se puedan iniciar referidos a derechos patrimoniales, siguen su trámite o deben iniciarse ante el juez de la quiebra (artículo 132 LCQ)

- Solo van a cobrar los acreedores, luego de cubiertos todos los gastos de honorarios y del propio proceso y según sus privilegios, aquellos sin privilegios cobran todos por igual de la suma conseguida con la liquidación.

Como en cualquier caso normado por la LCQ, la quiebra la pueden pedir los acreedores. Normalmente no lo hacen, ya que los gastos y los beneficios de este pedido no los favorecen cuando estamos ante pequeños deudores. Prefieren usualmente recurrir a la ejecución de distintos instrumentos en juicios 
rápidos (usualmente pagarés en juicios ejecutivos), así como a los descuentos en las cuentas bancarias.

En lo central, la quiebra puede pedirla el propio deudor, cuando se encuentra en un estado de cesación de pagos. La ley requiere de un hecho que exteriorice que el deudor se encuentra imposibilitado de cumplir regularmente sus obligaciones (art. 78 LCQ), brindando casos posibles (art. 79 LCQ) (El propio reconocimiento del deudor, la falta de pago a tiempo de las deudas, la ausencia del deudor sin dejar persona a cargo de los pagos, la venta de los bienes del deudor a precios mínimos, ocultación de los bienes o entrega de bienes en lugar de dinero -cuando la obligación sea de dinero- o recurrir a medios ruinosos o fraudulentos para obtener recursos)

La quiebra se cierra cuando se liquidan todos los bienes del deudor y con esa suma se paga cuanto sea posible de los honorarios, gastos y deudas. Normalmente en el caso de los consumidores, como vimos, la quiebra se clausura por falta de activo (art. 236 LCQ).

Luego de esto, el deudor no tiene obligación de pago sobre el remanente de las deudas que no se hayan podido pagar.

Transcurrido un año desde la sentencia de quiebra, el deudor vuelve a estar habilitado a disponer de sus nuevos bienes y tiene todas sus facultades (artículo 236 LCQ).

\section{La experiencia comparada en el tratamiento del sobreendeudamiento y el concurso o quiebra del consumidor}

Voy a tomar los ejemplos de Francia y Estados Unidos (6ta y 1era economía del mundo por su PBI, respectivamente) para ver como resuelven esta situación en esos países. Por diferentes caminos -en Francia hay un sistema mixto administrativo-judicial y en Estados Unidos se hace un proceso íntegramente judicial con juzgados especializados en bancarrota- ambos tratan con especificidad la situación particular del consumidor 
sobreendeudado, brindándole herramientas para poder salir de la misma.

\section{V.1. Francia $^{14}$}

El Derecho francés tiene un modelo propio para regular el fenómeno del sobreendeudamiento.

Frente a la constatación de dicha circunstancia, el ordenamiento francés ofrece vías y procedimientos de saneamiento diferentes según el tipo de deudor afectado.

Los comerciantes, artesanos, agricultores y profesionales independientes, en situación de endeudamiento excesivo, deben transitar el procedimiento judicial. Esta regulación se orienta a rescatar a los emprendedores, profesionales y empresas de la situación de ahogo económico y financiero para su rehabilitación en el mercado.

Esta vía de saneamiento, puede permitir al profesional o empresario o compañía deudora, reorganizar la actividad comercial o productiva, contar con un escenario de conciliación con los acreedores, acordar con ellos la cancelación del pasivo y mantener las fuentes de trabajo.

En el caso de los consumidores, la regulación se incorporó al Código de Consumo ("Code de la Consommtion") con un título especial dedicado al tratamiento de la situación de endeudamiento de los particulares, donde se consagran soluciones para sanear su situación de endeudamiento excesivo. La regulación encara vías alternativas de superación y rehabilitación.

El código define su ámbito de aplicación a partir de requisitos subjetivos y objetivos. Debe tratarse de una persona física (excluyendo, a las personas jurídicas) y deudor de buena fe. Desde lo subjetivo, se define también en sentido negativo. No

\footnotetext{
14 Ver JAPAZE, María Belén, Sobreendeudamiento del Consumidor: remedios preventivos y de saneamiento, Bibliotex, San Miguel de Tucumán, 2016, pags. 75-80
} 
debe ser ni comerciante, ni artesano, ni profesional, salvo que se trate de un endeudamiento que proceda de pasivos ajenos a esa actividad productiva o profesional.

Los requisitos objetivos se centran en la noción de sobreendeudamiento, que la ley caracteriza como "la imposibilidad manifiesta de hacer frente al conjunto de deudas no profesionales exigible y a vencer...".

Este cuadro de situación puede presentar alternativas diversas y diferentes serán también las soluciones previstas por la ley. El deudor en situación remediable tendrá determinadas herramientas a su alcance y el deudor en una situación irremediablemente comprometida, otras mucho más acotadas.

La normativa francesa de tratamiento de las situaciones de sobreendeudamiento contenida establece dos procedimientos diversos:

A. El redressement (rehabilitación) es un procedimiento al que puede acudir el deudor que se encuentra en una situación remediable, a desarrollarse en el ámbito administrativo y por ante la Comisión de Sobreendeudamiento creada a ese fin.

Se trata de un órgano de naturaleza administrativa, de composición mixta, en el que están presentes un representante del Estado en el Departamento (que actúa como Presidente), un tesorero-pagador general, un representante de los servicios fiscales, (es decir, de la Administración tributaria), otro del Banco de Francia (que actúa como Secretario) y dos, respectivamente, de entidades de crédito e inversión y de asociaciones familiares y de consumidores (escogidos ambos por el representante del Departamento de entre los propuestos por éstas). En cada Departamento existe al menos una Comisión, siendo competente territorialmente para conocer de este procedimiento la sita en el domicilio del deudor.

En ese marco y bajo la conducción del organismo mencionado se ofrece un escenario de actuación propicio para la búsqueda de soluciones ajustadas a la concreta situación del 
particular afectado. El procedimiento diseñado prevé un trámite en el que se abren puertas sucesivas. La Comisión de Sobreendeudamiento verifica los requisitos del caso, declara la apertura del procedimiento, dispone la notificación de los acreedores, hace una estimación del porcentual necesario para la manutención del grupo familiar del deudor, convoca para informar acerca del estado patrimonial del deudor y crea las condiciones para arribar a una solución consensuada sobre la base de un plan de pagos. En caso de que esta propuesta no alcance el consenso deseable entre consumidor $\mathrm{y}$ acreedores, se abre una nueva alternativa. La Comisión de Sobreendeudamiento está habilitada, ante el fracaso de la instancia conciliadora, a formular recomendaciones o disponer la adopción de medidas tales como la suspensión de las ejecuciones (salvo alimentarias), escalonar el pago de la deuda o parte de ella, imputar pagos al capital primero y luego a los intereses, reducir la tasa de interés acordada, etc., y el juez procederá a analizar las medidas peticionadas y el plan de pagos propuesto para rechazarlo o bien homologarlo. En esta última hipótesis el plan de saneamiento resulta obligatorio para los acreedores denunciados por el consumidor y para los que sin haber sido denunciados, fueron notificados y convocados por la Comisión de Sobreendeudamiento.

B. El retablissement personel (recuperación personal) del deudor es un procedimiento que tramita en el ámbito judicial, por ante un juez de ejecución, destinado al deudor que se encuentre en una situación irremediablemente comprometida. Está previsto por la ley para el supuesto en que resulta imposible o ineficaz transitar el procedimiento administrativo. Esta vía judicial tiene por finalidad la liquidación del patrimonio personal del deudor. Recibida la solicitud, el tribunal cita al deudor y sus acreedores a efectos de ofrecer información y dar inicio al procedimiento. Esta resolución implicará la suspensión inmediata de los juicios ejecutivos individuales que estuvieran en trámite, con la sola excepción de aquéllas ejecuciones 
destinadas a obtener el cumplimiento de deudas provenientes de obligaciones alimenticias.

El juez interviniente debe valuar los bienes y determinar el pasivo del deudor. Con los antecedentes aportados, el juez puede decretar la liquidación de la totalidad de los bienes embargables, designando un martillero para ello.

Entre los bienes exentos, o de carácter inembargable, destacan las cosas muebles que integran el hogar y que se estimen necesarios para el diario vivir del deudor y los bienes necesarios para el desempeño de su profesión u oficio. Si los fondos obtenidos con el proceso son suficientes para realizar el pago de las obligaciones, el juez resolverá cerrar el procedimiento. No obstante resultar insuficientes para cubrir el pasivo, si lo estimara procedente -a la luz de la buena fe del deudor-, el juez también puede declarar la clausura del procedimiento y la exoneración de las deudas insatisfechas, con excepción de las expresamente previstas.

\section{V.2. Estados Unidos ${ }^{15}$}

El llamado modelo de fresh start o volver a empezar que se utiliza en los Estados Unidos, pone el énfasis en esta segunda oportunidad, que se le ofrece al consumidor sobreendeudado para recuperarlo lo antes posible para la actividad económica y de consumo. Se considera que una función básica de los procesos de quiebra es atender a los mercados de crédito, propiciando que el acceso sea fácil y abierto, al igual que la salida de los mismos.

Bajo este sistema se entiende que toda la sociedad se beneficia de la liberación del deudor, en tanto, exonerado de su pasivo pendiente, ésta recupera un miembro que puede ser productivo para la sociedad. Es la denominada teoría de la utilidad social o teoría humanitaria. Cuando un hombre bonesto tiene

\footnotetext{
15 CUENA CASAS, Matilde, Fresh Start y Mercado Crediticio, en http://www.indret.com/ pdf/842_es.pdf.
} 
mala suerte y quiebra financieramente, la sociedad no gana nada manteniéndolo bundido y, sobre todo, ello no beneficia a los acreedores puesto que de igual manera no van a ver satisfechos sus créditos por cuanto la supervivencia de sus derechos de crédito bloquea la capacidad productiva del deudor y por tanto, la posibilidad de cobro por parte de aquéllos.

La normativa concursal norteamericana ${ }^{16}$ se ofrece en el título 11 de las leyes federales (U.S. Code). Se trata de un régimen unificado, abarcativo de todas las soluciones frente a la insolvencia, sea que afecten a los particulares y sus economías domésticas o al sector empresario. Concretamente, respecto de las personas físicas, la regulación propone cuatro tipos de procedimientos bajo el U.S. Bankruptcy Code: a.- el capítulo 7 relativo a la liquidación; b.- el capítulo 11, relativo a la reorganización de los créditos; c.- el capítulo 12, relativo a las explotaciones agrarias o pesqueras familiares con ingresos regulares; y d.- el capítulo 13 relativo a personas físicas con ingresos regulares. No obstante el catálogo de opciones, los capítulos 7 y 13 fueron siempre las alternativas transitadas por los particulares en crisis por deudas propias del consumo moderno.

En el primero de ellos (Capítulo 7 , de la liquidación) ${ }^{17}$, el deudor que lo promueve, debe presentarse ante el juez correspondiente, peticionar la apertura del procedimiento, indicar con precisión su estado patrimonial -con detalle de sus bienes y deudas-, beneficiándose automáticamente con la paralización de todas las acciones de cobro que se hubieran promovido en su contra. Esta suspensión incluye aún a los acreedores que cuentan con una garantía real. Los titulares de tales acreencias podrán eventualmente obtener la autorización del juzgado interviniente para continuar con la ejecución o iniciar otras acciones judiciales.

\footnotetext{
16 Ver https://www.usbankruptcycode.org/

17 https://www.usbankruptcycode.org/chapter-7-liquidation/
} 
Se produce el desapoderamiento de los bienes del deudor (con excepción de los exentos que la ley de cada Estado determina) que se liquidan a fin de que las sumas obtenidas sean objeto de distribución entre los acreedores, conforme las reglas de preferencias legalmente establecidas.

Verificado el desapoderamiento de los bienes no exentos, incorporado el producido de tales activos al patrimonio del concurso y cumplido el procedimiento de distribución entre los acreedores, el deudor queda liberado de toda responsabilidad. En mérito a la operatividad del beneficio de condonación de deudas al que accede, el deudor persona física queda habilitado para retomar su actuación en el mercado y el comenzar de nuevo (fresh start).

Pese a la simpleza aparente, la normativa impone al deudor que pretende acceder a este beneficio, superar un estricto test de discharge (Test de Descarga).

En general la realización de cualquier actuación tendente a perjudicar a los acreedores comporta la exclusión del deudor del procedimiento del capítulo.

Puntualmente una causa de exclusión particular, es el haber obtenido el beneficio de la discharge en un procedimiento iniciado dentro de los ocho años anteriores a la petición, o el no haber completado el curso de asesoramiento financiero legalmente previsto.

El fiduciario o cualquier acreedor puede invocar la concurrencia de las causas de exclusión ante el Tribunal y peticionar la denegación del beneficio. Frente a la denuncia de alguno de estos extremos, se ordenará al fiduciario la investigación correspondiente, y en su caso, el beneficio de la discharge será revocado por el Tribunal, hasta un año después de su concesión.

La decisión vinculada a la revocación del beneficio debe adoptarse a instancia de parte y previa audiencia de los interesados. 
La segunda vía de acceso a la liberación del pasivo es la prevista en el Capítulo $13^{18}$. El inicio de este procedimiento supone que el deudor encuentre un escenario de negociación con sus acreedores a fin de acordar un plan de pagos con su consiguiente cronograma de cumplimiento, que será afrontado con todos sus ingresos disponibles y luego de dejar establecida la cuantía necesaria para solventar sus gastos personales y familiares. A partir de la solicitud de apertura del procedimiento y por tres o cinco años -dependiendo del nivel de ingresos del deudor-, la totalidad de los mismos -menos lo necesario para su manutención- es gestionada por el administrador concursal (el bankrupty trustee). Este modelo permite al deudor mantener la propiedad de sus bienes.

El procedimiento requiere que se trate de personas físicas con ingresos regulares, que concurra buena fe en el solicitante y que sus deudas vencidas y líquidas se encuentren por debajo de un límite legal.

Transcurrido el tiempo legalmente establecido, el deudor que cumple el plan de pagos accede al beneficio de la liberación de deudas, con excepción de los derechos de garantía que recaen sobre los bienes afectados.

O sea, repasando, podemos ver que el deudor que quiere empezar de cero (fresh start), puede entregar todos sus bienes no exentos, y empezar de nuevo, presentando el trámite del capítulo 7. Ahora bien, si pretende conservar sus bienes, deberá acomodar la solicitud al capítulo 13 y esperar durante tres o cinco años, pudiendo volver a empezar de cero, saldando las deudas restantes.

En el año 2005, se aprobó en EEUU una modificación en el régimen legal de insolvencia, hasta entonces vigente. La ley concursal aprobada tuvo el apoyo de los dos partidos políticos mayoritarios. 18 https://www.usbankruptcycode.org/chapter-13-adjustment-of-debts-of-an-individual-
with-regular-income/ 
¿Que fue lo que ocurrió? Frente al notable incremento de las solicitudes de concurso y de liberación del pasivo insatisfecho, el lobby de las entidades financieras instaló el mensaje que el procedimiento legal vigente hasta ese momento, alentaba la utilización del mismo en forma distorsiva, permitiendo abusos que para el sector de la banca eran intolerables. Nada dijeron que el incremento de los concursos iba aparejado al del crédito al consumo. Se sostenía que los consumidores se endeudaban irresponsablemente para luego buscar el auxilio del proceso concursal.

La reforma del año 2005 determinó la imposición de nuevos requisitos formales al procedimiento de insolvencia. Se imponen asimismo, nuevos requisitos sustanciales tanto para el acceso como para la salida del mismo.

Uno de los requisitos incorporados en la reforma, que condiciona el acceso al procedimiento, está vinculado a la obligatoriedad de un asesoramiento financiero previo.

Antes de la reforma de 2005, la persona física que pretendía acogerse al procedimiento de condonación de deuda, podía consultar un abogado, completar los formularios previstos para el inicio del trámite, pagaba una tasa correspondiente y solicitaba la apertura del procedimiento concursal. Luego de la reforma, ese mismo consumidor debe someterse a un asesoramiento crediticio (credit counseling ${ }^{19}$ ) dentro de los 180 días anteriores a la solicitud, para poder ser declarado en concurso. El asesoramiento crediticio debe ser proporcionado por un asesor de la lista que a tal efecto confecciona y aprueba la Secretaría de Justicia ${ }^{20}$. El deudor no puede acceder al procedimiento concursal si no acredita con la certificación correspondiente, que ha recibido tal asesoramiento crediticio.

\footnotetext{
19 https://www.uscourts.gov/services-forms/bankruptcy/credit-counseling-and-debtoreducation-courses

20 https://www.justice.gov/ust/list-credit-counseling-agencies-approved-pursuant11-usc-111
} 
Declarada la apertura del proceso y durante su desarrollo, el deudor debe recibir formación crediticia adicional ${ }^{21}$ pues de no mantener esta suerte de educación en el crédito, podrá denegársele la exoneración de las deudas pendientes.

La imposición de un nuevo requisito condiciona también la libre elección del procedimiento. El llamado test de recursos (Means Test) es un mecanismo que permite establecer qué deudor puede acogerse a los distintos modelos de discharge (descarga) previstos en la legislación concursal. Se acude a una complicada fórmula que somete a prueba la capacidad patrimonial del consumidor para el pago de sus deudas y por la que se procura incrementar el tránsito por el capítulo 13 (cumplimiento de un plan de pagos para recién alcanzar la exoneración del pasivo). Esta disposición opera como barrera de acceso al mecanismo de descarga del capítulo 7 (por el que se libera al deudor de sus deudas pendientes con cesión de la totalidad del patrimonio no exento y no sujeto a derechos de garantía)

\section{Proyectos actuales que tratan la prevención y saneamiento del consumidor sobreendeudado en nuestro país}

En la República Argentina, los proyectos de modificación de la Ley de Defensa del Consumidor presentado en el marco del plan de Justicia 2020 y el ante proyecto de modificación de la Ley de Concursos y Quiebras elaborado por la comisión redactora impulsada por el Ministerio de Justicia de la Nación (en la misma sintonía, el proyecto presentado por el Diputado Martin Llaryora $^{22}$ ) tratan en la dirección que entiendo correcta la difícil

\footnotetext{
21 https://www.justice.gov/ust/list-approved-providers-personal-financial-managementinstructional-courses-debtor-education

22 Expte 7210-D-2018 (Cámara de Diputados de la Nación Argentina) Proyecto de Ley de Procedimiento Concursal para Consumidores Sobreendeudados (Personas humanas que no realizan actividad económica organizada) Autor Dip. Nac. Por la Provincia de Córdoba, Martín Llaryora.
} 
situación que afrontan todos los consumidores que acumulan deudas hoy impagables en nuestro país.

\section{VI.1 Ante proyecto de Ley de Defensa del Consumidor}

En el caso del ante proyecto de nueva Ley de Defensa del Consumidor, en lo que atañe específicamente al tema de este artículo, se puede concluir que regula correctamente la problemática del crédito al consumo y el sobreendeudamiento de los consumidores. Respecto a este último punto fundamentalmente instrumenta mecanismos preventivos y llama a que se implemente medidas de corte sustancial y procedimental para poder lograr el saneamiento de ese consumidor tapado por las deudas ${ }^{23}$.

Es importante volver a remarcar que define al sobreendeudamiento del consumidor ${ }^{24}$ como la situación caracterizada por la grave dificultad para afrontar el cumplimiento de las obligaciones exigibles o de pronta exigibilidad, que compromete el acceso y el goce de bienes esenciales.

Vale decir que el ante proyecto establece e impone claramente el principio de préstamo responsable ${ }^{25}$, poniendo obligaciones concretas en cabeza de los dadores de crédito o financiamiento. Se deja establecido que los costos derivados del otorgamiento de créditos en infracción al principio mencionado, serán afrontados total o parcialmente por el proveedor o intermediario del mismo.

En cuanto a la actividad publicitaria, se impone un contenido informativo mínimo ${ }^{26}$ que deben tener los anuncios. A su vez, se establece un deber de asistencia, asesoramiento y advertencia ${ }^{27}$ que debe ser particular a cada tomador de crédito

\footnotetext{
23 Arts. 82 y 84 Ante Proyecto Ley de Defensa del Consumidor. https://www.justicia2020. gob.ar/wp-content/uploads/2018/12/Anteproyecto-Ley-Defensa-del-Consumidor-_VFD_.pdf

24 Art. 81 Ante Proyecto Ley de Defensa del Consumidor.

25 Art. 79 Ante Proyecto Ley de Defensa del Consumidor.

26 Art 85 Ante Proyecto Ley de Defensa del Consumidor.

27 Arts. 86, 87 y 88 Ante Proyecto Ley de Defensa del Consumidor.
} 
Se reconocen expresamente al consumidor dos derechos que pueden contribuir a la prevención del endeudamiento excesivo; el derecho al pago anticipado del crédito ${ }^{28}$ o de la financiación acordada y el derecho al arrepentimiento ${ }^{29}$, regulándose el modo de ejercicio y los efectos derivados.

Se regula el Pagaré de Consumo ${ }^{30}$, estableciendo que si una obligación de dar dinero emergente de una relación de consumo se instrumenta en con un pagaré, se regirá por la Ley de Defensa del Consumidor y subsidiariamente por otras normas generales y especiales. Establece que deberá contener el documento, la totalidad de la información requerida por el art. 85 (descripción del bien o servicio que se financia, monto total del préstamo, sistema de amortización, intereses, comisiones, gastos, duración de contrato de crédito, etc.).

Una importante decisión para evitar la toma de decisiones irreflexivas en cuanto a créditos, prolegómeno en algunos casos del sobreendeudamiento, es establecer que se entenderá como práctica abusiva no imponer al consumidor tomador de créditos un desembolso inicial obligatorio ${ }^{31}$.

\section{VI.2 Ante Proyecto de la Comisión Reformadora de la Ley 24.522}

Por Resolución No 1163 del Ministerio de Justicia de la Nación de fecha 22 de mayo de 2015, bajo la gestión del Ministro Julio C. Alak, se creó la Comisión de Reforma de la Ley 24.522 encomendándole la adecuación del régimen concursal aplicable a los "pequeños procesos" y proveer la necesaria reforma a la ley de concursos y quiebras $\mathrm{N}^{\circ} 24.522$ a fin de incorporar el sobreendeudamiento del consumidor y la microempresa. La Comisión se integró con los juristas Héctor Osvaldo CHOMER,

\footnotetext{
28 Art. 95 Ante Proyecto Ley de Defensa del Consumidor.

29 Art. 96 Ante Proyecto Ley de Defensa del Consumidor.

30 Art. 91 Ante Proyecto Ley de Defensa del Consumidor.

31 Art. 94 Ante Proyecto Ley de Defensa del Consumidor. Op Cit
} 
Daniel Roque VÍTOLO, Juan Carlos VEIGA, Francisco JUNYENT BAS, Alejandra Noemí TÉVEZ, Emiliano GARCÍA CUERVA y Marcelo Eduardo HAISSINER. La Comisión presentó el Anteproyecto de ley elaborado al Ministerio de Justicia que lo derivó a la Secretaría Legal y Técnica de la Presidencia de la Nación para su consideración.

El Anteproyecto, propone, por un lado, reformar el capítulo de los denominados "De los pequeños concursos y quiebras" (Capítulo IV de la ley concursal), para adecuarlos a los requerimientos que la doctrina viene formulando desde hace tiempo.

Pero la gran novedad de la reforma impulsada en este Anteproyecto, y es específico al tema en tratamiento, es la incorporación del Capítulo V, dedicado al "Concurso de las personas humanas que no realizan actividad económica organizada y otros sujetos".

El art. 304 define el presupuesto objetivo: "Es presupuesto para la apertura del proceso regulado en el presente capítulo que el sujeto peticionante se encuentre: 1) En estado de cesación de pagos; 2) En dificultades económicas o financieras de carácter general; o 3) Sobreendeudado. A efectos de este artículo se entenderá por sujeto sobre endeudado a aquel que presente, en su patrimonio, un desequilibrio significativo entre su activo ejecutable y las obligaciones por las cuales dicho activo deba responder".

Por su parte, el art. 305 precisa quiénes son los destinatarios de esta regulación particular. Establece la norma citada que "Pueden acceder voluntariamente al procedimiento previsto en este Capítulo las personas humanas que: 1) No realicen una actividad económica organizada ni resulten titulares de una empresa o establecimiento comercial, industrial, agropecuario o de servicios; 2) Realicen una actividad como empleados públicos o privados en relación de dependencia; 3) Ejerzan una profesión liberal no organizada bajo forma de empresa; 4) Realicen una actividad autónoma e independiente no organizada bajo la forma de empresa. La circunstancia de que dichas personas 
humanas se encuentren inscriptas como empleadores y tengan personal en relación de dependencia en número no mayor a tres (3) trabajadores, no obstará a su inclusión dentro del régimen regulado por el presente capítulo".

En orden a la legitimación activa, se establece que "El procedimiento podrá ser solicitado exclusivamente por el deudor, o por apoderado con facultad especial" (art. 307).

El Juez puede rechazar la petición, cuando el deudor: 1) No sea sujeto susceptible de acceder al procedimiento regulado en el capítulo; 2) Si no se ha dado cumplimiento al artículo 308; 3) Si se encuentra dentro del período de inhibición para una nueva presentación 4) Cuando la causa no sea de su competencia. (Art. 310)

El juez deberá designar un conciliador de la lista para que intervenga en el procedimiento. Los conciliadores sólo podrán ser abogados o contadores. Ante el Conciliador y en su domicilio, los acreedores formularan sus pedidos de verificación de sus créditos dentro de los 10 días de la fecha de publicación del último edicto

El art. 312 está dedicado a los efectos de la apertura del procedimiento. Dispone la norma que "La apertura del procedimiento produce los siguientes efectos: 1) La suspensión por noventa (90) días de todos los juicios de contenido patrimonial por causa o título anterior a su presentación, no pudiendo deducirse nuevas acciones con fundamento en tales causas o títulos, incluidas la ejecución de créditos prendarios y/o hipotecarios y desalojos de la vivienda particular del deudor o del lugar donde lleva a cabo su labor profesional. Los expedientes permanecerán en los Juzgados originariamente asignados y los acreedores deberán acreditar su condición con copia certificada a presentar ante el conciliador, cuando sean convocados a los efectos de su reconocimiento. 2) La suspensión de los intereses de los créditos del deudor, con excepción de los créditos garantizados con garantís reales que prosiguen en le medida que alcance el asiento del crédito. 3) Quedan sin efecto todas las 
medidas cautelares trabadas sobre los bienes y honorarios del deudor, y en especial, los embargos sobre los sueldos, salarios. 4) El conciliador tiene las facultades de contralor de la situación patrimonial del deudor, aplicándose el régimen establecido por los art. 15 y 16 de la presente ley, a cuyo fin el juez puede autorizar para tutela personal del deudor y de su familia el pago de las cuotas correspondientes a las coberturas de salud de obras sociales o empresas de medicina prepaga. 5) La apertura de la etapa de conciliación, la cual se extenderá por noventa (90) días desde la última publicación de edictos, en el cual el conciliador tendrá por misión promover y facilitar acuerdos entre el deudor y sus acreedores".

La figura del conciliador y la previsión de un período de conciliación que se extiende por 90 días, es quizás lo novedoso. El conciliador tendrá por misión determinar provisionalmente el pasivo y facilitar acuerdos entre el deudor y sus acreedores. El mismo recibe la documentación que le presenten los acreedores y corrobora la denuncia del deudor, a los fines de procurar celebrar acuerdos, para la satisfacción de las obligaciones pendientes de cumplimiento. Los acreedores tendrán un plazo de diez (10) días desde la última publicación de edictos para presentarse ante el conciliador a solicitar la verificación de sus créditos. Vencido dicho plazo y en igual término, el conciliador deberá informar al juez la nómina detallada de los acreedores cuya verificación o admisibilidad recomienda, como así también de las eventuales exclusiones acompañando la documentación pertinente en sus respectivos legajos. El juez en el plazo de diez (10) días, deberá dictar la sentencia de verificación. El funcionario promoverá el proceso conciliatorio y podrá celebrar tantas audiencias como considere necesarias, convocando a ellas al deudor y a los acreedores. La etapa concluye por el vencimiento del plazo de 90 días o cuando se obtuviere la conformidad de acreedores que representen la mayoría absoluta del capital verificado y declarado admisible. En caso de no lograrse acuerdo, el conciliador propondrá una fórmula de repago y o cualquier otra solución que estime conveniente ante el Juez. 
La resolución vinculada al acuerdo y su eventual impugnación es motivo de regulación en el art. 318 donde el juez procederá a realizar el control de legalidad formal y sustancial de los acuerdos, analizando las impugnaciones que pudieran existir, eventualmente, habilitar un nuevo período conciliatorio por treinta (30) días a cuyo fin dará nueva intervención al conciliador, homologar el acuerdo en caso que lo estime ajustado a derecho o bien imponer un plan de reorganización que considere razonable, valorando la naturaleza de créditos, origen, el contexto social y familiar del deudor y su conducta, tanto antes como durante el proceso. En todos los casos, el juez tiene facultades para integrar el acuerdo, mediante resolución fundada, aumentando o reduciendo plazos y adecuando los montos de las cuotas pactadas, en tanto considere pertinente a fin de asegurar el cumplimiento de lo acordado sin afectar subsistencia decorosa del deudor y la de su familia.

Una vez ejecutado el acuerdo el deudor podrá peticionar se declare su cumplimiento y el levantamiento de la inhibición originariamente trabada. Cuando el deudor no cumpla el acuerdo total o parcialmente, a instancia de acreedor interesado, el juez podrá derivar el conflicto al conciliador, a fin de que se intente una nueva negociación conclusiva del asunto (Art. 320)

El art. 321 establece que "el deudor no podrá presentar una nueva petición para el sometimiento al régimen de este capítulo, hasta después de haber transcurrido 1(un) año, contando a partir de la fecha de cumplimiento del acuerdo o del plan de reorganización impuesto por el tribunal, o de la clausura del proceso liquidatorio".

La liquidación de los bienes del deudor es regulada en los arts. 322 a 326. Allí se dispone que en caso de que la conciliación fracasara, ante la imposibilidad de cumplir cualquier medida de saneamiento, el juez mediante resolución fundada abrirá el proceso liquidatorio, disponiendo la realización de los bienes, implicando el desapoderamiento de los bienes del deudor existentes a la fecha de la resolución del juez. El conciliador debe 
presentar en el plazo de treinta (30) días de iniciada la liquidación un informe general con el contenido del art. 39. Luego este mismo deberá presentar el informe final sobre el producido de los bienes y el respectivo proyecto de distribución.

Sin duda ninguna, la novedad de la regulación propuesta es la recepción del mecanismo de liberación del deudor o descarga de deuda, consagrado en el art. 327. La norma prevé que "una vez realizados los bienes, si el producido del activo no alcanzare para pagar los créditos se procederá al prorrateo de los fondos debiendo abonarse en primer lugar los gastos de justicia y el saldo entre los acreedores reconocidos, respetando en su caso el régimen de privilegios dispuesto en la presente ley. Una vez distribuido el resultado, el juez dictará una resolución en la que declarará extinguidas todas las deudas que tuviese el deudor vinculadas con el proceso, salvo los gastos de justicia, las obligaciones alimentarias, y los que constituyan créditos originados en daños a la persona humana por daño moral y por daño material derivado de lesiones a la integridad psicofisica, no pudiendo ningún acreedor reclamar en el futuro saldo insoluto alguno. El juez podrá imponer al deudor la realización de cursos dirigidos a la educación para el consumo con la finalidad de orientarlo y prevenir los riesgos que pudieran derivarse del consumo de productos o de la utilización de servicios, como así también ayudarlo a evaluar alternativas y emplear los recursos en forma eficiente, con el objeto de evitar que puedan producirse situaciones futuras que l coloquen nuevamente bajo los presupuestos señalados en el art. 304".

La temática de los honorarios de los letrados de las partes y funcionarios intervinientes es tratada en el art. 329, que reza: "La regulación de honorarios del letrado del deudor, de los conciliadores y demás funcionarios se regirá por el presente artículo que tiene carácter de orden público. A esos fines, la regulación de honorarios en la etapa conciliatoria se establecerá entre el 3 y el $6 \%$ del pasivo verificado, y el juez tiene facultades para distribuir los porcentajes que corresponda a cada uno de los profesionales intervinientes. A todo evento, se establece 
un piso regulatorio de 4 salarios mínimos vitales y móviles. En caso de liquidación judicial, la escala será del 5 al 8\% del activo realizado y/o el pasivo verificado, el que sea mayor, con idéntico piso mínimo. Las costas en el proceso conciliatorio están a cargo del deudor, el que podrá enfrentarlas en cuotas, de conformidad a lo que resuelva el juez al homologar el acuerdo. En el caso de liquidación judicial, al no extinguirse los gastos de justicia, las sumas que queden adeudadas en concepto de bonorarios deberán abonarse por el deudor, pudiendo a esos fines solicitar un régimen de cuotas al tribunal, el que previa vista a los funcionarios resolverá en definitiva el modo de pago, pudiendo aplicar el art. 271".

\section{VI.2 Proyecto de Ley de Procedimiento Concursal para Consumidores Sobreendeudados}

Como bien lo expresa el Diputado Llaryora en los Fundamentos del Proyecto de Ley (Expte 7210-D-2018, Proyecto de Ley de Procedimiento Concursal para Consumidores Sobreendeudados) en la redacción del mismo se tuvo especialmente presente el proyecto analizado en el punto anterior. De hecho es la base del mismo. Cabe decir que en este caso la diferencia es el planteo en forma autónoma del proceso planteado y no como una modificación al régimen de concursos y quiebras vigentes.

\section{Conclusión}

Donde hay pobreza y hambre no hay mercado. Donde no hay mercado, no hay inversión. Donde no hay inversión, no hay empleo.

La profunda crisis que atraviesa nuestro país, necesita remedios que principalmente protejan a los más perjudicados del sistema; los consumidores, las pymes, los emprendedores. El consumo del mercado interno está asociado íntimamente a las posibilidades de inversión y creación masiva de empleo. Para recuperar el consumo y recrear el mercado interno, se 
necesitan -entre otras cosas- herramientas legales que ayuden a respirar a esos sectores, ahogados financieramente por el actual esquema económico.

¿Cuáles son las herramientas legales que pueden ayudar? Para la prevención del sobreendeudamiento el capítulo mencionado de proyectos de modificación de la Ley de Defensa del Consumidor presentado en el marco del plan de Justicia 2020 es un avance positivo. Y para el saneamiento de dicha situación una vez que se consumó, es importante que se impulse o bien la modificación a la Ley de Concursos y Quiebras realizada y propuesta por la Comisión de Reforma de la Ley 24.522, o en su defecto, el impulso del proyecto de Ley de Procedimiento Concursal para Consumidores Sobreendeudados, que toma como base el proyecto de reforma de la Comisión.

Ayudar al saneamiento de la situación del consumidor sobreendeudado, y permitirle volver a niveles de vida dignos, van en la dirección correcta para aportar a la reactivación y crecimiento con equidad que necesita nuestro país. 